\title{
Histopathological Investigation of Different MCAO Modalities and Impact of Autologous Bone Marrow Mononuclear Cell Administration in an Ovine Stroke Model
}

\author{
Johannes Boltze • Björn Nitzsche • Kathrin D. Geiger • \\ Heinz-Adolf Schoon
}

Received: 14 June 2011 /Revised: 27 July 2011 / Accepted: 28 July 2011 / Published online: 23 August 2011

(C) Springer Science+Business Media, LLC 2011

\begin{abstract}
Translational researchers and clinicians recommend the use of large animal models in preclinical stroke research. This represents an important part of a strategy aiming to prevent past translational failures in future therapeutic developments. Thirty-five Merino rams were subjected to sham surgery $(n=3)$, one-branch middle cerebral artery occlusion (MCAO, $n=8$ ) or total MCAO $(n=24)$. Twelve animals from the latter group received intravenous administration of $4 \times 10^{6}$ autologous mononuclear bone marrow cells (BM MNC) per kilogram $24 \mathrm{~h}$ after total MCAO. Animals were sacrificed at day 49 post MCAO. Histological investigations were performed to reveal (1) the impact of different MCAO modalities on a cellular level and (2) the influence of BM MNC therapy
\end{abstract}

$\overline{\text { Johannes Boltze and Björn Nitzsche contributed equally to this work }}$

J. Boltze $(\triangle) \cdot$ B. Nitzsche

Fraunhofer Institute for Cell Therapy and Immunology,

Perlickstraße 1,

04103 Leipzig, Germany

e-mail: johannes.boltze@izi.fraunhofer.de

J. Boltze $\cdot$ B. Nitzsche

Translational Centre for Regenerative Medicine,

University of Leipzig,

Philipp-Rosenthal-Straße 55,

04103 Leipzig, Germany

B. Nitzsche $\cdot$ H.-A. Schoon

Institute of Pathology, Faculty of Veterinary Medicine,

University of Leipzig,

An den Tierkliniken 33,

04103 Leipzig, Germany

\section{K. D. Geiger}

Department of Neuropathology, Institute for Pathology, Medical

Faculty Carl Gustav Carus, Technical University of Dresden,

Fetscherstraße 74

01307 Dresden, Germany following stroke. Clear differences between one-branch and total MCAO were observed histologically with results being comparable to those seen in human patients. BM $\mathrm{MNC}$ treatment reduced final lesion extension, lymphocytic infiltration and axonal degeneration after MCAO. The sheep model may represent a feasible tool for translational stroke research as pathohistological findings mimic the situation in humans. Histological evidence was found for beneficial impact of autologous BM MNC therapy. Further studies are needed to assess the neurofunctional impact of the approach in the gyrencephalic brain.

Keywords Stroke - Brain ischaemia - Large animal model Cell therapy Neuroprotection · Translational research

\section{Introduction}

Ischaemic stroke represents a major cause of death and is the most prominent reason for permanent disability in adulthood [1]. The only effective and FDA-approved therapy for the disease is intravenous thrombolysis [2]. The narrow time window of $4.5 \mathrm{~h}$ following onset of ischaemia [3] and numerous contraindications [4] still exclude the majority of patients $(>95 \%)$ from treatment [5]. Thus, novel therapeutic options for ischaemic stroke are strongly demanded. Cell therapies, in particular the use of bone-marrow-derived (stem) cell populations, are among the most promising approaches [6]. Efficacy and safety of bone marrow stromal cells (BMSC) and mononuclear cells (BM MNC) has been shown in preclinical experiments. Neuroprotective, immunomodulatory and plasticityenhancing properties of BMSC [7-9] and BM MNC [1012], rather than direct cell replacement by differentiation and integration, were reported as mediators of beneficial 
effects. Excellent data is available on the therapeutic time window for BM MNC treatment [13, 14], while autologous application of those cells is considered relatively uncritical in human patients. Moreover, first in-man studies revealed safety of intravenous and intra-arterial [15] application of autologous BM MNC following stroke in humans, encouraging further clinical research on this treatment paradigm.

However, numerous therapeutic strategies for focal cerebral ischaemia had been developed during the last decades, predominantly focussing on post-stroke neuroprotection. Despite promising preclinical results and successful safety assessments in patients [16] in many cases, not a single approach was proven to be effective in clinical trials [17]. The reasons for this disappointing situation are considered numerous. There is a common understanding that suboptimal design of preclinical experiments and improper animal models may at least partially account for this dilemma. Consequently, more thorough and rigorous standards for preclinical research were demanded by translational stroke researchers and clinicians. The "Stem Cell Therapy as an Emerging Paradigm for Stroke" (STEPS) international expert consortium published recommendations for cell-based stroke research $[18,19]$ in order to enhance the predictive value of animal experiments and thereby to reduce the risk of failure of an experimental treatment approach in the clinic. An important recommendation is to test a therapeutic candidate in large animal models of stroke to estimate its influence in the gyrencephalic brain [19].

Numerous large animal models of middle cerebral artery occlusion (MCAO) including the use of canine [20], feline [21] and non-human primates [22] species are available. Albeit being of utmost importance for stroke research, invasive experimental and surgical procedures (e.g. enucleation to assess the MCA) in these models may lead to high post-stroke mortality [23], thus limiting applicability for long-term safety and efficacy assessments. An alternative ovine MCAO model was recently introduced by our group [24], which allows control of lesion size as well as neurofunctional impact, implementation of modern imaging techniques and long-term survival of experimental subjects. The pathological findings in this model are basically comparable to those obtained in human stroke victims. However, more detailed knowledge about the histopathological consequences of MCAO is needed to enhance the use of the sheep model in translational stroke research. This holds particularly true for cell therapy research, as distinct modulations on the cellular level are expected to be the major mode of actions in cell therapies for stroke [6]. Here, we describe (1) the pathohistological impact of permanent partial and total cortical MCAO and (2) provide first data regarding the impact of autologous BM MNC therapy in this model.

\section{Materials and Methods}

\section{Experimental Subjects}

All experiments were approved by the commission for animal welfare at the regional board of Leipzig (animal license numbers $05 / 04$ and 16/07). A total number of 35 hornless Merino rams with an average weight of 60.3 (45$100) \mathrm{kg}$ and average age of $10.2(8-18)$ months were enrolled in this study. Animals were housed in groups of up to six rams in capacious stable boxes (minimum $2.5 \mathrm{~m}^{2}$ per animal) with ad libitum access to food and water at the Faculty for Veterinary Medicine, University of Leipzig. Prior to surgery and starting 5 days thereafter, rams were allowed to graze on areas next to the stable for at least $5 \mathrm{~h}$ per day. Food (but not water) restriction was applied $24 \mathrm{~h}$ before surgery.

\section{Study Design and Induction of Focal Cerebral Ischaemia}

Animals were assigned to the following experimental groups: sham surgery $(n=3)$, one-branch (partial) MCAO $(n=8)$, total MCAO without $(n=12)$ or with $(n=12)$ application of autologous BM MNC $24 \mathrm{~h}$ after stroke.

MCAO in the left hemisphere was induced as described elsewhere [24]. Briefly, animals were initially anaesthetised by intravenous injection of $4.0 \mathrm{mg} / \mathrm{kg}$ ketamine (Medistar Ltd., Holzwickede, Germany), $0.1 \mathrm{mg} / \mathrm{kg}$ xylazine (Ceva Sante Animal Ltd., La Ballastiére, France) and $0.2 \mathrm{mg} / \mathrm{kg}$ midazolame (Braun Melsungen, Melsungen, Germany). Intramuscular buprenorphine $\left(0.01 \mathrm{mg} / \mathrm{kg}\right.$, Temgesic $^{\circledR}$, RB Pharmaceuticals, Berkshire, UK) was used for periand postsurgical pain management. After loss of consciousness, subjects were immediately intubated and quickly transferred to the operating room. Anaesthesia was maintained by respiration with $2 \%$ isofluran (WDT eG, Garbsen, Germany) in $30 \%$ oxygen. Continuous monitoring of electrocardiogram, blood pressure, blood oxygenation, expiratory carbon dioxide content and body temperature (rectal) was performed. After local antiseptic treatment, an elliptic skin flap was removed from the shaved skin between the eye and the ear, followed by electrocoagulation of the temporal artery and vein. After incision at the temporal line, the temporal muscle was transiently elevated from the parietal skull bone. A small trepanation of approximately $1 \times 1 \mathrm{~cm}$ was performed behind the orbital rim for direct access to the MCA. Following incision of the dura, the artery was touched by bipolar forceps (sham group). Alternatively, either the caudal parietal MCA branch (partial MCAO) or the entire cortical vessel (regularly also supplying subcortical areas) was occluded (total MCAO). The temporal muscle was refixed to the temporal line using 2-0 resorbable filaments (Vicryl 2-0, 
Ethicon, Norderstedt, Germany). After suturing of the skin wound using identical surgical filaments and final superficial antiseptic/antibiotic treatment, animals were taken back to the stable and were allowed to recover. Intravenous antibiotic and analgetic treatment by $5 \mathrm{mg} / \mathrm{kg}$ enrofloxacin and $2.2 \mathrm{mg} / \mathrm{kg}$ flunixin, respectively, was performed for 7 days post-surgery. Daily inspections and health checks were performed by skilled veterinarians until the end of the trial. All animal survived the procedure and quickly recovered from surgery.

Isolation of BM MNC, Baseline Infarct Volumetry and Autologous Cell Transplantation

Twenty hours after MCAO, animals were again weighted and re-anaesthetized by intravenous injection as described above. Subjects were placed in prone position and the areas around both iliac crests were shaved. Following superficial antiseptic treatment, bone marrow specimens (approximately 60 to $80 \mathrm{~mL}$ ) were collected in 20,000 IU of heparin in two sterile $50-\mathrm{mL}$ perfusor syringes by repeated puncture of the iliac crests on both sides. Bone marrow punctuate was transferred immediately to a clean bench for further processing. The volume of BM aspirates was doubled by adding sterile phosphate-buffered saline (PBS, Biochrom AG, Berlin, Germany). MNC were obtained by density gradient centrifugation using a 1:1 $(v / v)$ mixture of LSM $1077^{\circledR}(1.077 \mathrm{~g} / \mathrm{mL}$, PAA Laboratories GmbH, Cölbe, Germany) and Pancoll ${ }^{\circledR}(1.089 \mathrm{~g} / \mathrm{mL}$, PAN-Biotech $\mathrm{GmbH}$, Aidenbach, Germany) at $1,000 \times g$ for $25 \mathrm{~min}$. After two washing steps in PBS, the number of vital BM MNC was assessed using the Trypan Blue ${ }^{\circledR}$ (Sigma-Aldrich $\mathrm{GmbH}$, Hamburg, Germany) method and a Neubauer counting chamber (Carl-Roth GmbH, Karlsruhe, Germany). During the time of BM MNC separation, animals were subjected to $1.5 \mathrm{~T}$ turbo spin echo (T2 TSE) magnetic resonance imaging (MRI) to reveal initial lesion size in all groups. Please refer to [24] for methodological details. A weightadapted transplantation paradigm was applied. Immediately before transplantation, $4 \times 10^{6}$ autologous BM MNC per kilogram bodyweight were stored in $20 \mathrm{~mL}$ of PBS and injected intravenously $24 \mathrm{~h}$ following MCAO (directly after MRI), within 15 min after assessment of cell viability.

Termination of Study and Histological Investigations

Seven weeks after MCAO, animals were euthanized by intravenous injection of $15 \mathrm{~mL}$ pentobarbital (Eutha77 ${ }^{\circledR}$, Essex Pharma Ltd, Munich, Germany) after induction of deep anaesthesia. Heart action was monitored continuously. Death was confirmed by two independent veterinarians after heart beats and respiratory movements were clearly absent for at least $2 \mathrm{~min}$. Animals were then rapidly decapitated at the atlanto-occipital junction. Both carotid arteries were exposed and blunt $2 \mathrm{~mm}$ perfusion cannulas were inserted into each vessel. The heads were perfused with $1.5 \mathrm{~L}$ PBS, followed by $15 \mathrm{~L} 4 \%$ paraformaldehyde (PFA). The skull cap was carefully removed with an oscillating saw (HEBUmedical AG, Tuttlingen, Germany) and the dura was opened. Afterwards, the heads were stored for at least $24 \mathrm{~h}$ in 4\% PFA for immersion fixation before the brain was removed for further processing.

Gross Pathology and Volumetry

After removal, PFA-fixed brains were weighted and largest vertical and horizontal (including cerebellum) circumferences were measured. Brains were further photographed from each side using a Nikon DX 100 digital camera. Thereafter, $4 \mathrm{~mm}$ coronal brain slices were cut (Fig. 1a) and photographed from the rostral and occipital direction. From digital photographs, the surface area of the infarct, the area of the ipsilateral (ischaemic) and the contralateral hemisphere (without ventricles), as well as the areas of the corresponding lateral ventricles were calculated for each slice $\left(A_{\mathrm{r}}=\right.$ area from rostral view, $A_{\mathrm{o}}=$ area from occipital view, in square centimetres, Fig. 1b) using the Image J 1.39 open source software [25]. The total volumes $\left(V_{\text {total }}\right)$ of both hemispheres and lateral ventricles were calculated as follows:

$V_{\text {total }}=\sum^{n} V_{\text {part }}$

where $V_{\text {part }}$ (volume derived from individual brain slice) is

$V_{\mathrm{part}}=\frac{A_{r}+A_{o}+\sqrt{A_{r} \times A_{o}}}{3} \times 0.4 \mathrm{~cm}$

and $n$ is the number of partial volumes (slices) for the individual brain (ranging from 17 to 19). The ventricular expansion $(v E)$ in the ischaemic hemisphere at day 49 post MCAO was calculated as follows:

$v E=\frac{V_{\text {total }}^{[l e V]}}{V_{\text {total }}^{[r i V]}}$

whereas $V_{\text {total }}^{[l e V]}$ represents the total volume of the left (ischaemic side) lateral ventricle and $V_{\text {total }}^{[\mathrm{riV}]}$ indicates the total volume of the right lateral ventricle, respectively. All investigations were performed by a researcher not aware of the group allocation.

Preparation of Brain Slices for Histological Investigations

For histological studies, two consecutive 4-mm slices were analysed from three different areas of the infarct: two slices each from the rostral and occipital border of the infarction, 

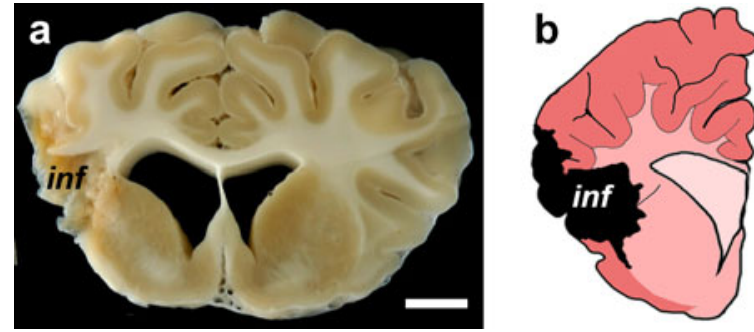

Fig. 1 Gross pathology and brain analysis. Four-millimetre-thick brain slices were taken from brains after fixation, photographed and used for further analysis (a, occipital view). To calculate ventricular expansion, total volumes of hemispheres and ventricles were calculated from the areas of the ipsilateral hemisphere (dark (grey matter) and middle (white matter) red, without infarct) and ventricle (light red) as well as contralateral hemisphere (dark (grey matter) and middle (white matter) blue) and ventricle (light blue, all given in b) according to Eqs. 1 to 3 in "Materials and Methods". For histological investigations of two consecutive slices from three defined regions

and two slices from the level of MCAO (central part of the lesion). All slices were analysed in four different regions: the ipsilateral (left) leptomeninx in the area of the MCA, the central lesion zone, the bordering (200 $\mu \mathrm{m}$ wide) reactive zone as well as the unaffected remote zone (Fig. 1c) in accordance to [26]. In both, the reactive and the remote zone, grey (cortical) and white (medullary) matters (Fig. 1c) were distinguished for separate analysis. Where appropriate, a comparison to corresponding areas in the contralateral (right) hemisphere (Fig. 1c) was also performed. Brain slices were embedded in paraffin (HyperCenter $^{\circledR}$, Shandon, Germany). From each zone, 4- $\mu$ m thick slices were cut using a microtome (Medim $\mathrm{GmbH}$, Gießen, Germany) and mounted on SuperFrost ${ }^{\circledR}$ slides (Carl-Roth $\mathrm{GmbH}$, Karlsruhe, Germany) for staining and microscopic analysis.

\section{Histological Stainings}

All slices were alternately stained with hematoxylin and eosin (HE, for morphological assessments) or more specialized (Picrosirius red and Kossa) stainings.

HE staining [27] was employed to assess proliferation of connective tissue, perivascular cellular infiltrations, blood vessel density and signs of hypoxic-ischaemic neuronal alterations. The latter comprise spheroids (indicating axonal degeneration) and cytolytic neuronal alterations (e.g. "ghost" neurons) [26]. Previous histological studies [24] revealed that ovine microglia can be stained using antiCD11b and biotinylated potato (Solanum tuberosum) lectin (STL), which, however, may also label neutrophils (CD11b) and capillary walls (STL). Therefore, HE staining was also used to identify recruited microglial cells by their rodshaped nucleus [26].
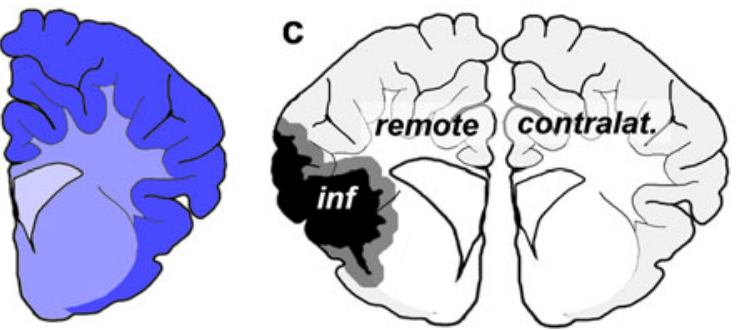

(rostral and occipital border of infarction, and level of MCAO) infarcted areas (black area, with adherent leptomeninx) were discriminated from the bordering reactive zone ( $200 \mu \mathrm{m}$ broad, dark grey), and the remote zone in the ipsilateral hemisphere (c). In the remote and reactive zone, grey and white matter areas where analysed separately. Where appropriate, comparison to corresponding areas in the contralateral hemisphere was also drawn. Scale bar in (a) indicates $1 \mathrm{~cm}$. inf infarct, remote remote zone, contralat. contralateral hemisphere

Kossa (Ko) staining [27] was applied for visualisation of focal or diffuse mineral deposits ("calcification", black staining). Picrosirius red (PsR) staining [28, 29] was used to describe morphology and also proliferation of connective tissue resulting in collagen fibres appearing red, bluestained mucopolysaccharids appearing, and brown nuclei. Polarized light (see below) was further used to detect (yellow) collagen type I and (green) type III fibres [28].

\section{Microscopy and Histological Evaluation of Brain Specimen}

Histological analysis was performed by a researcher trained in veterinary pathology. In case of doubts, senior veterinary and human pathologists were consulted. All investigators were unaware of group allocation of investigated specimen.

An Olympus BH2 microscope (Olympus $\mathrm{GmbH}$, Hamburg, Germany) equipped with $\times 4, \times 10, \times 20$ and $\times 40$ objectives as well as a polarisation filter (for visualisation of collagen fibres) was used for histological slice assessment. Evaluation and graduation of findings was performed in a semiquantitative manner by score point allocation (minimum, 0 ; maximum, 3) according to common neuropathological criteria (Table 1). As an exception, the degree of mineral deposits was multiplied with a second score describing distribution (focal, 1; multifocal, 2 and diffuse, 3; thus resulting in minimum, 0 and maximum, 9; see Table 2).

\section{Statistical Analyses}

The SPSS statistical software (version 16.0.2; SPSS Inc., Chicago) was used for all statistical analyses. The Kolmogorov-Smirmov test was applied to check for normal distribution of data. As the majority of data was not normally distributed or ordinally scaled, only non-parametrical tests 
Table 1 Criteria for histological evaluation of ovine brain specimen in hematoxylin-eosine and Picrosirius red staining

Degree of alteration (score points)

\begin{tabular}{|c|c|c|c|c|c|}
\hline Aspect & Staining & $\begin{array}{l}\text { No pathology }(0) \\
\text { Leptomeninx }\end{array}$ & Mild (1) & Moderate (2) & Severe (3) \\
\hline $\begin{array}{l}\text { Proliferation of } \\
\text { connective tissue }\end{array}$ & $\begin{array}{l}\text { HE } \\
\text { PsR }\end{array}$ & $\begin{array}{l}\text { No or very few }(0-4)^{\mathrm{a}} \\
\text { fibroblasts }\end{array}$ & Few $(5-9)^{\mathrm{a}}$ fibroblasts & $\begin{array}{l}\text { Moderate numbers }(10-50)^{\mathrm{a}} \\
\text { of fibroblasts, collagen } \\
\text { fibres in subarachnoidal } \\
\text { space }\end{array}$ & $\begin{array}{l}\text { Many }(>50)^{\mathrm{a}} \text { fibroblasts, } \\
\text { subarachnoidal space } \\
\text { and pia mater cannot be } \\
\text { discriminated }\end{array}$ \\
\hline \multirow[t]{2}{*}{$\begin{array}{l}\text { Infiltration with } \\
\text { lymphocytes and } \\
\text { plasma cells }\end{array}$} & $\mathrm{HE}$ & None & Focally few $(<10)^{\mathrm{a}}$ cells & $\begin{array}{l}\text { Multifocally moderate } \\
(10-50)^{\mathrm{a}} \text { numbers of cells }\end{array}$ & $\begin{array}{l}\text { Multifocally many }(>50)^{\mathrm{a}} \\
\text { cells or diffuse infiltration }\end{array}$ \\
\hline & & Central zone (necrosis) & & & \\
\hline $\begin{array}{l}\text { Proliferation of } \\
\text { connective tissue }\end{array}$ & $\begin{array}{l}\mathrm{HE} \\
\text { PsR }\end{array}$ & $\begin{array}{l}\text { No or very few }(0-4)^{\mathrm{a}} \\
\text { fibroblasts }\end{array}$ & $\begin{array}{l}\text { Few }(4-9)^{\mathrm{a}} \text { fibroblasts, } \\
\text { scattered collagen fibres }\end{array}$ & $\begin{array}{l}\text { Moderate numbers }(10-50)^{\mathrm{a}} \\
\text { of fibroblasts, multifocally } \\
\text { dense collagen fibres }\end{array}$ & $\begin{array}{l}\text { Many }(>50)^{\mathrm{a}} \text { fibroblasts, pia } \\
\text { mater and collagen fibres } \\
\text { in the necrotic area cannot } \\
\text { be discriminated }\end{array}$ \\
\hline $\begin{array}{l}\text { Infiltration with } \\
\text { lymphocytes and } \\
\text { plasma cells }\end{array}$ & $\mathrm{HE}$ & None & Focally few $(<10)^{\mathrm{a}}$ cells & $\begin{array}{l}\text { Multifocally moderate } \\
(10-50)^{\mathrm{a}} \text { numbers of cells }\end{array}$ & $\begin{array}{l}\text { Multifocally many }(>50)^{\mathrm{a}} \\
\text { cells or diffuse infiltration }\end{array}$ \\
\hline \multirow[t]{2}{*}{ Blood vessel density } & $\mathrm{HE}$ & No blood vessels & $\begin{array}{l}\text { Low density of blood } \\
\text { vessels }(<10)^{\mathrm{a}}\end{array}$ & $\begin{array}{l}\text { Moderate density of blood } \\
\text { vessels }(10-30)^{\mathrm{a}}\end{array}$ & $\begin{array}{l}\text { High density of blood } \\
\text { vessels }(>30)^{\mathrm{a}}\end{array}$ \\
\hline & & \multicolumn{4}{|c|}{ Reactive and remote zone, contralateral hemisphere } \\
\hline $\begin{array}{l}\text { Cytolytic neuronal } \\
\text { alterations }{ }^{\mathrm{b}}\end{array}$ & $\mathrm{HE}$ & None & Few $(<10 \%)^{\mathrm{a}}$ & Moderate $(10-30 \%)^{\mathrm{a}}$ & Many $(>30 \%)^{\mathrm{a}}$ \\
\hline Spheroids ${ }^{c}$ & $\mathrm{HE}$ & None & Few $(1-4)^{\mathrm{a}}$ & Moderate $(5-20)^{\mathrm{a}}$ & Many $(>20)^{\mathrm{a}}$ \\
\hline Blood vessel density ${ }^{\mathrm{c}, \mathrm{d}}$ & $\mathrm{HE}$ & Not increased ${ }^{\mathrm{d}}$ & $\begin{array}{l}\text { Slightly increased }{ }^{\mathrm{d}} \\
(+10 \% \text { or less })^{\mathrm{a}}\end{array}$ & $\begin{array}{l}\text { Moderately increased } \\
\quad(+10 \text { to }+30 \%)^{\mathrm{d}}\end{array}$ & $\begin{array}{l}\text { Massively increased }{ }^{\mathrm{d}} \\
(+30 \% \text { or more })^{\mathrm{a}}\end{array}$ \\
\hline $\begin{array}{l}\text { Perivascular infiltration } \\
\text { with lymphocytes and } \\
\text { plasma cells }\end{array}$ & $\mathrm{HE}$ & None & Focally few $(1-4)^{\mathrm{a}}$ cells & $\begin{array}{l}\text { Multifocally moderate } \\
(5-20)^{\mathrm{a}} \text { numbers of cells }\end{array}$ & $\begin{array}{l}\text { Multifocally many }(>20)^{\mathrm{a}} \\
\text { cells or diffuse infiltration }\end{array}$ \\
\hline Microglial recruitment & $\mathrm{HE}$ & $\begin{array}{l}\text { Not relevantly } \\
\text { increased }^{\mathrm{e}}(<20)^{\mathrm{a}}\end{array}$ & $\begin{array}{l}\text { Slightly increased }{ }^{\mathrm{e}} \\
(20-30)^{\mathrm{a}}\end{array}$ & $\begin{array}{l}\text { Moderately increased } \\
\quad(30-60)^{\mathrm{e}}\end{array}$ & Massively increased ${ }^{\mathrm{e}}(>60)^{\mathrm{a}}$ \\
\hline
\end{tabular}

${ }^{\text {a }}$ Refers to microscopic field of view at $\times 10$ magnification

${ }^{\mathrm{b}}$ Grey matter only

${ }^{\mathrm{c}}$ Grey and white matter

${ }^{\mathrm{d}}$ Refers to corresponding area in contralateral hemisphere

${ }^{\mathrm{e}}$ Refers to corresponding area in contralateral hemisphere of non-stroked (sham) animals

were applied for all analyses. The Wilcoxon test was applied for pair-wise comparison, whereas the Mann-Whitney $U$ test was applied for group comparison. A $p$ value $<0.05$ was considered statistically significant.

All data are presented as median values \pm standard error of the mean (SEM; for non-ordinally scaled data only) or box plots (white line, median; box edges, $25 \%$ and $75 \%$ percentile; whiskers, $95 \%$ confidence interval). The asterisk symbol (*) indicates a statistical difference against total MCAO, whereas the pound sign (\#) indicates difference against partial MCAO. Single symbols represent $p$ values $<0.05$, and double symbols indicate $p$ values $<0.01$.
Table 2 Criteria for histological evaluation of mineral deposits in the ovine brain specimen using Kossa staining

${ }^{a}$ Refers to microscopic field of view at $\times 10$ magnification

\begin{tabular}{lllll}
\hline \multicolumn{4}{l}{ Degree of alteration (score points) } & \\
\hline Aspect & No pathology (0) & Mild (1) & Moderate (2) & Severe (3) \\
Mineral deposits & None & 1 to $20^{\mathrm{a}}$ & 20 to $50^{\mathrm{a}}$ & $>50^{\mathrm{a}}$ \\
& Distribution (factor for multiplication) & & \\
& & focal: $\mathrm{x} 1$ & multifocal: $\mathrm{x} 2$ & diffuse: $\mathrm{x} 3$ \\
\hline
\end{tabular}




\section{Results}

Animal Welfare, Survival Rates and Transplanted Cell Numbers

No animal died or had to be euthanized due to poor conditions (e.g. not qualified for grazing, infectious diseases and fever for more than 3 days, weight loss $>15 \%$, moving inability, stupor) before completion of the trial. The intended number of $4 \times 10^{6}$ BM MNC per kilogram of bodyweight was obtained from each animal that was assigned to the cell transplantation group.

Part I: Pathohistological Impact of Permanent Partial and Total MCAO

\section{Gross Pathology and Volumetry}

Analysis of MRI data revealed significant differences in ischaemic lesion size between partial and total MCAO at day 1 post MCAO (Fig. $2 \mathrm{a}$ and $\mathrm{b} ; p<0.01$ ). After brain removal, data regarding brain weight and circumferences at day 49 were recorded (Table 3) and brains were photographed. Lesion surface area was assessed from digital micrographs. The surface area of the lesion was significantly larger in the total MCAO group as compared to the partial MCAO $\left(21.5 \pm 2.2 \mathrm{~cm}^{2}\right.$ versus $7.6 \pm 1.0 \mathrm{~cm}^{2}$; Fig. $2 \mathrm{c}$ and $\mathrm{d} ; p<0.01)$. Similar findings were obtained for the ventricular expansion (total MCAO 2.9 \pm 0.3 versus partial MCAO 1.6 \pm 0.2 ; Fig. 2e and f; $p<0.01)$. No signs of cerebral infarction or ventricular expansion were found in sham-treated subjects. However, a small area of slightly thickened and opaque leptomeninx (mean extension, 2.6 \pm $1.0 \mathrm{~cm}^{2}$ ) was observed in the area of surgery in all shamoperated animals (statistical significance given in brackets in Fig. 2c; white dotted line indicates affected area in Fig. 2d).

\section{Histological Findings in the Leptomeninx}

Besides the aforementioned thickened and opaque leptomenix in the area of craniotomy, no further pathological

\section{a}

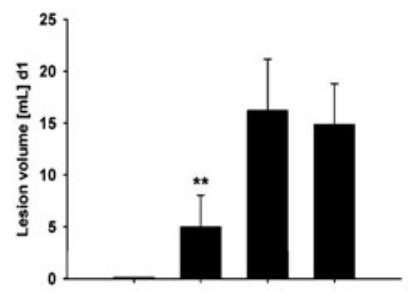

C

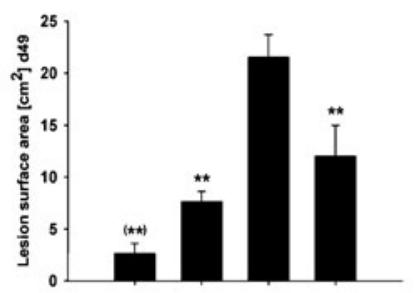

e

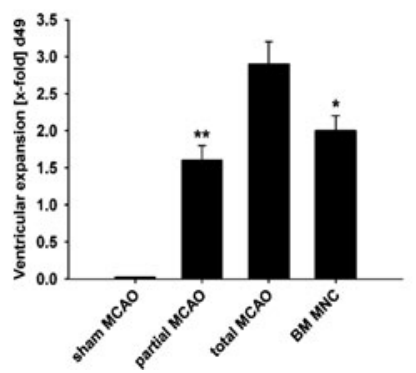

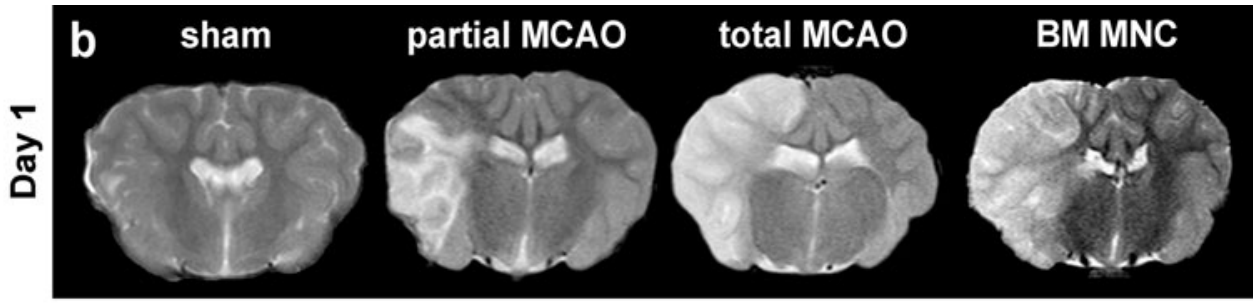
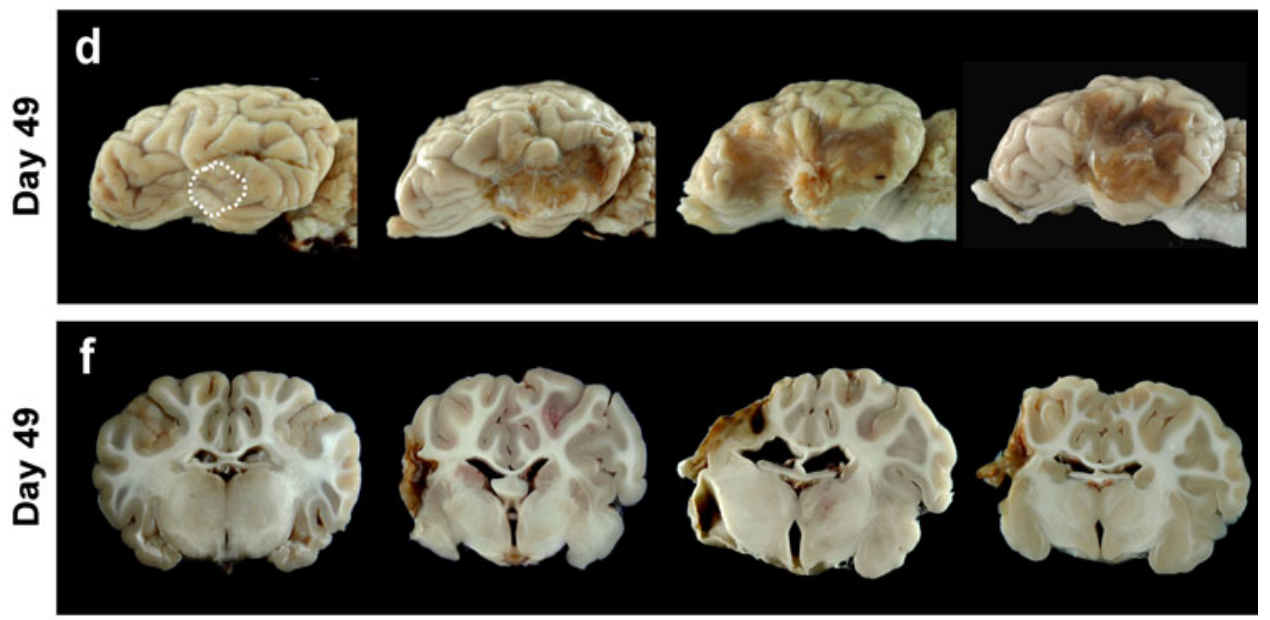

Fig. 2 Lesion size assessment and gross pathology. A clear difference between sham, partial and total MCAO was observed at day 1 following MCAO in T2 TSE MRI scans (a and b). However, no initial differences in lesion size were observed between total MCAO without or with BM MNC administration. At day 49, lesion surface measurement revealed smaller lesion sizes in partial MCAO and BM
MNC subjects as compared to total MCAO (c). Slight leptomeningeal alterations in the area of trepanation were regularly observed in shamtreated animals (d, white dotted line), being much smaller than a total MCAO lesion (c, $p<0.01$, significance given in brackets). Measurement of ventricular expansion revealed similar findings (e and $\mathbf{f}$ ). $* / * * p<0.05 / 0.01$ versus total MCAO 
Table 3 Brain weights and largest brain circumferences

\begin{tabular}{lllll}
\hline Group & Parameter & $\begin{array}{l}\text { Brain weight } \\
{[\mathrm{g}]}\end{array}$ & $\begin{array}{l}\text { Horizontal circumference } \\
{[\mathrm{cm}]}\end{array}$ & $\begin{array}{l}\text { Vertical circumference } \\
{[\mathrm{cm}]}\end{array}$ \\
\hline Sham $(n=3)$ & Mean \pm SEM & $106.0 \pm 4.4$ & $22.1 \pm 0.8$ & $13.4 \pm 1.0$ \\
& Min-max & $99-114$ & $19-24$ & $9-16$ \\
Partial MCAO $(n=8)$ & Mean \pm SEM & $113.1 \pm 5.3$ & $23.4 \pm 0.4$ & $16.2 \pm 0.6$ \\
& Min-max & $93-139$ & $22-26$ & $13-18$ \\
Total MCAO $(n=12)$ & Mean \pm SEM & $120.1 \pm 4.5$ & $19.8 \pm 1.3$ & $11.8 \pm 1.3$ \\
& Min-max & $97-140$ & $13-25$ & $8-18$ \\
BM MNC $(n=12)$ & Mean \pm SEM & $118.0 \pm 2.2$ & $23.7 \pm 0.5$ & $15.5 \pm 0.6$ \\
& Min-max & $104-137$ & $17-25$ & $9-18$ \\
\hline
\end{tabular}

findings (in this and all other zones) were observed in sham-operated subjects. A mild to moderate, chronic and active (non-infectious) fibrosis with mild infiltration of mononuclear cells into the leptomeninx was observed in all animals subjected to MCAO. The assessment of connective tissue proliferation according to Table 1 showed no differences between partial MCAO and total MCAO in the lesioned (Fig. 3a and $\mathrm{c}-\mathrm{f}$ ) and contralateral (Fig. 3b) hemisphere $(p>0.05)$, but a non-surprising overall increase of connective tissue in comparison to the contralateral hemisphere (Fig. 3a and b). Lymphocytic infiltration in the leptomeninx was comparable between partial and total
MCAO, with a non-significant $(p>0.05)$ enhancement of lymphocytes in the total MCAO group (Fig. $3 g-m$ ).

\section{Histological Findings in the Central Zone}

Moderate, but statistically significant differences between the groups were observed regarding the proliferation of connective tissue in the central necrotic zone. Connective tissue proliferation was slightly enhanced in the partial MCAO as compared to the total MCAO group $(p<0.05$, Fig. $4 \mathrm{a}-\mathrm{c}$ ). No differences were observed regarding blood vessel density ( $p>0.4$, Fig. $4 d$ and e). However, perivas-
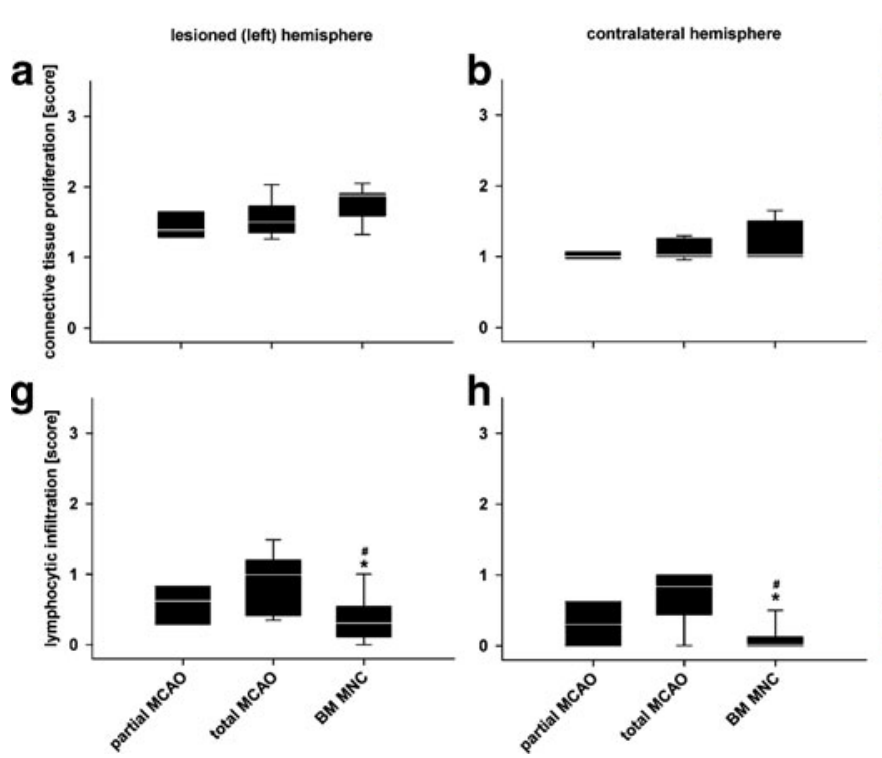

Fig. 3 Leptomeningeal findings following MCAO. An active chronic fibrosis was observed (a and b) in all groups subjected to middle cerebral artery occlusion with or without BM MNC (c to f, HE staining). Only a slight increase of connective tissue proliferation was observed in sham-treated subjects (c). Infiltration with lymphocytes was observed in all groups (i to $\mathbf{m}$, HE staining, white arrows). Lymphocytic infiltration was lowest in BM MNC-treated subjects (g,

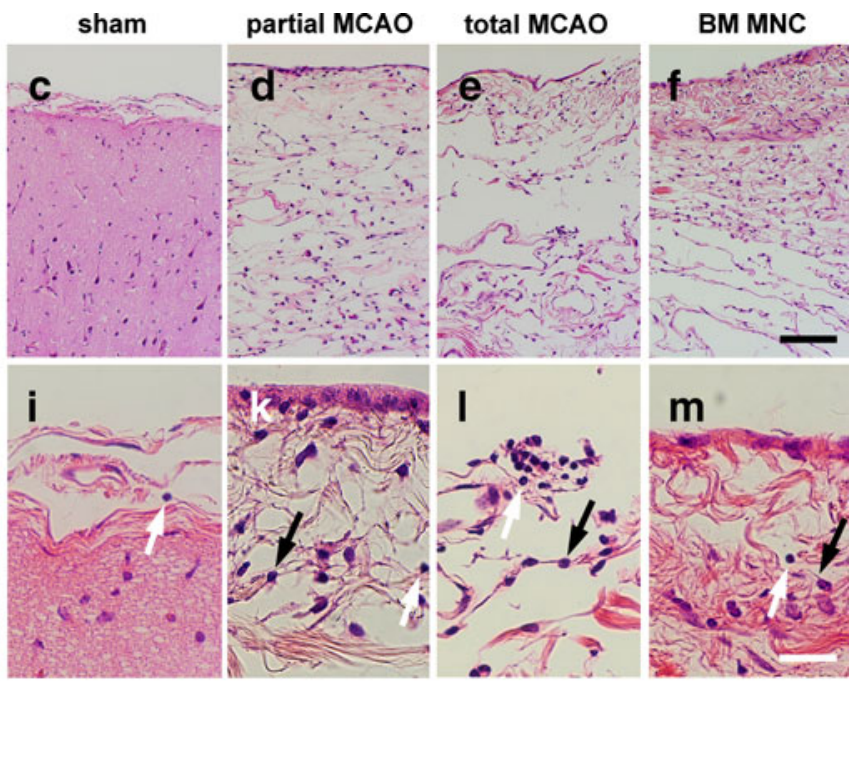

h) in both hemispheres and compared to partial and total MCAO. Please note augmentation of fibroblasts (k to $\mathbf{m}$, black arrows) in all groups subjected to MCAO. Graphs: white line in box plots indicates the median, whiskers give the $95 \%$ confidence interval. $* / \# p<0.05$ versus total MCAO/partial MCAO. Scale bar in (f) represents $100 \mu \mathrm{m}$ in (c) to (f) and scale bar in (m) indicates $25 \mu \mathrm{m}$ in (i) to (m), respectively 
Fig. 4 Histological findings in the central zone. Proliferation of connective tissue was slightly enhanced in the partial MCAO and BM MNC group (a and $\mathbf{b}$, Picrosirius red). In polarisation microscopy, connective tissue was identified as collagen type I (yellow, c) and type III (green, c, Picrosirius red). Blood vessel density was comparable between all groups (d) and numerous blood vessels could be identified in the infarct core (c, white arrow; e, black arrows, Picrosirius red). Lymphocytic infiltration was less in both, the partial MCAO and BM MNC group as compared to total MCAO (f, $p<0.01)$. Lymphocytes (g, white arrows, HE) were mostly found together with vast macrophages/foamy fat cells. No inter-group differences (but highest medians) were observed for mineral deposits (h) in the central zone of BM MNC-treated subjects. Calcifications could clearly be identified by black staining (i, white arrows, Kossa). All photomicrographs presented were taken from a total MCAO subject. Graphs: white line in box plots indicates the median, whiskers give the $95 \%$ confidence interval. Pia pia mater, $c z$ central zone (former ischaemic core). $* / * * p<0.05 / 0.01$ versus total MCAO. Scale bars in (b) and (c) represent $100 \mu \mathrm{m}$ and scale bars in (e), (g) and (i) represent $50 \mu \mathrm{m}$
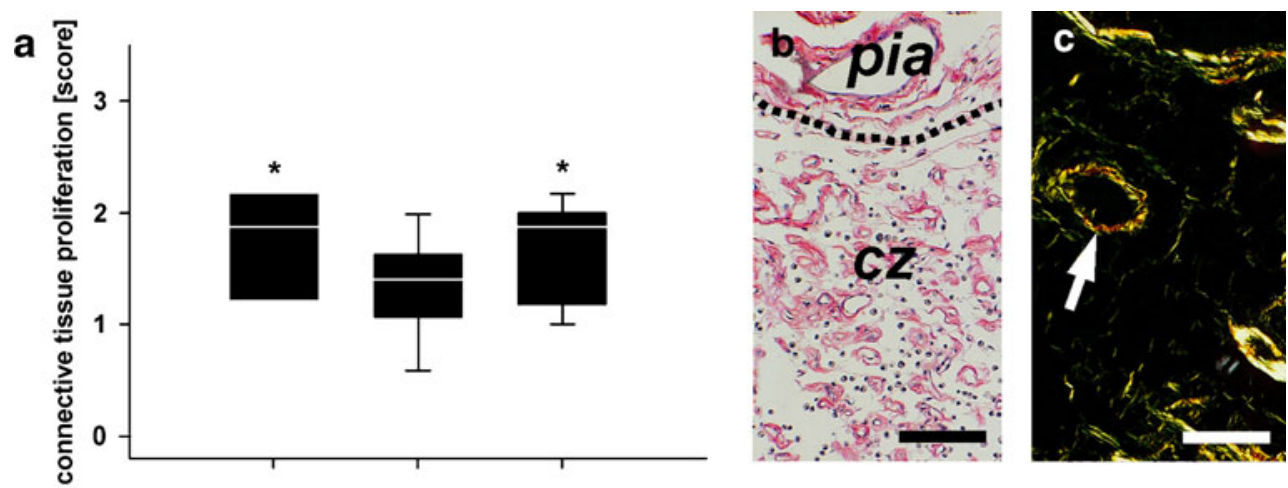

d
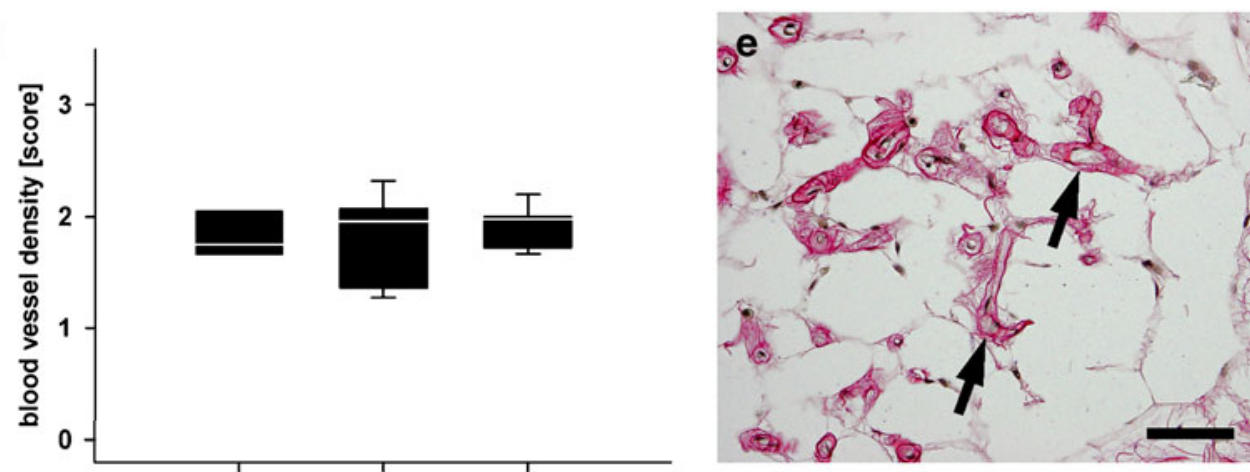

f
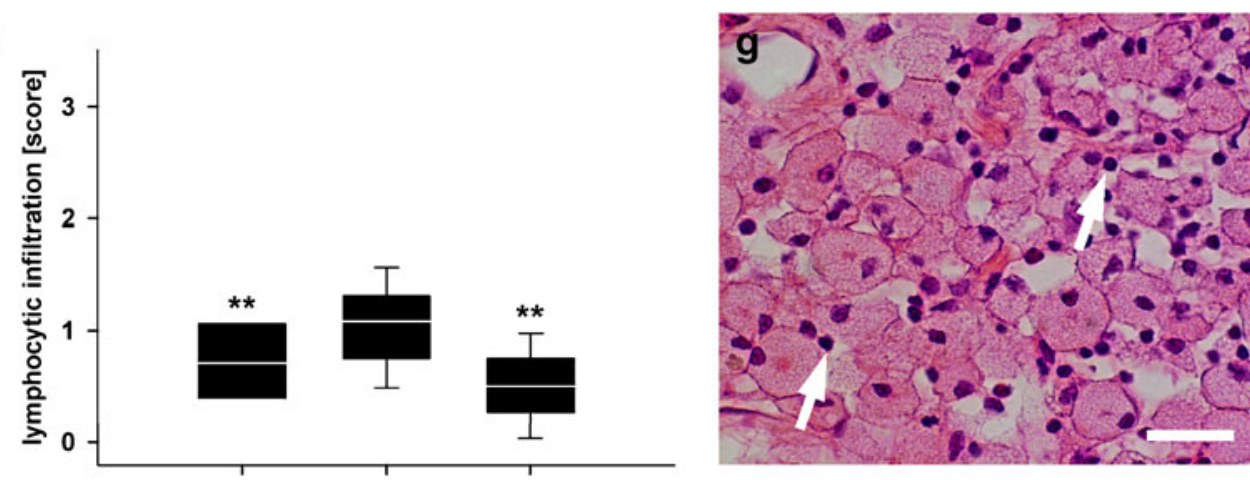

h
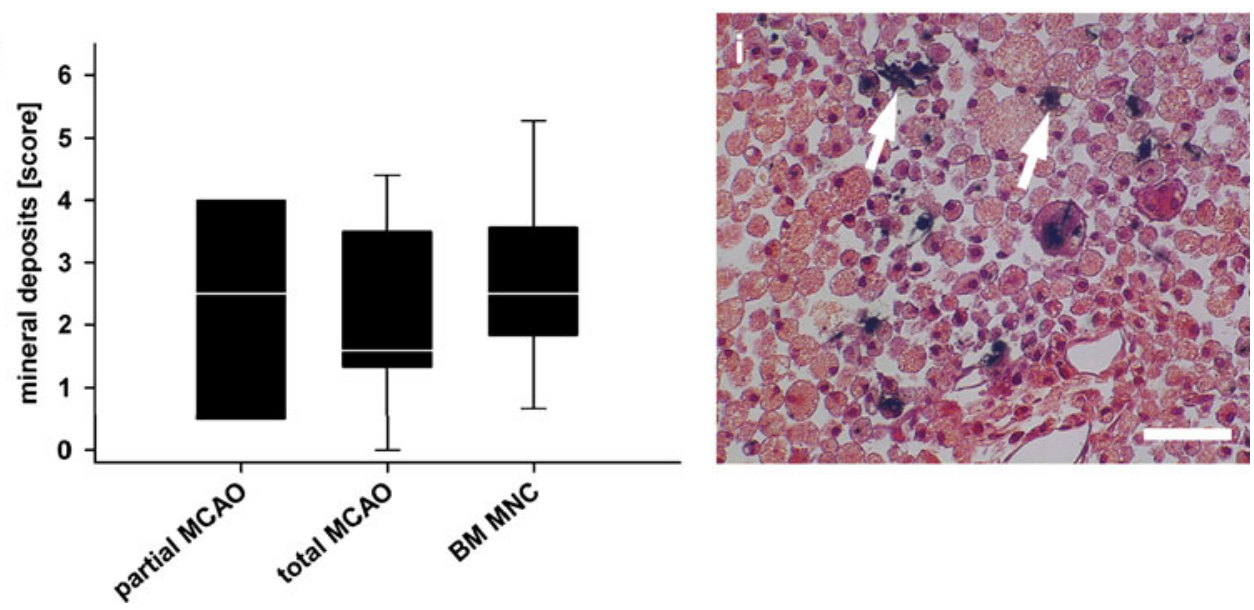

cular lymphocytic infiltration was significantly lower in the partial MCAO than in the total MCAO group $(p<0.01$, Fig. 4f and g). Distribution and amount of mineral deposits were similar between both groups ( $p>0.05$, Fig. $4 \mathrm{~h}$ and i). Representative micrographs from the total MCAO group for all criteria investigated are given in Fig. 4. 


\section{Histological Findings in the Reactive Grey and White Matter Zones}

As previously reported [24], the reactive zone bordering the central lesion was demarked by reactive gliosis, which is typical after stroke. Almost no cytolytic neurons were found in the reactive grey matter (cortical) zones of the partial MCAO group 49 days after MCAO. In contrast, scattered post-ischaemic ("ghost") neurons (black asterisks in Fig. 5a and $n$ ) could still be identified in the reactive cortical areas of total MCAO subjects ( $p<0.01$, quantitative data not shown). Spheroids (Fig. 5a and b), a typical sign of axonal degeneration, were found in small numbers in the cortical reactive zones of both groups. The number of spheroids observed in the partial and total MCAO groups were statistically indifferent ( $p>0.05$, Fig. $5 b)$. As expected,
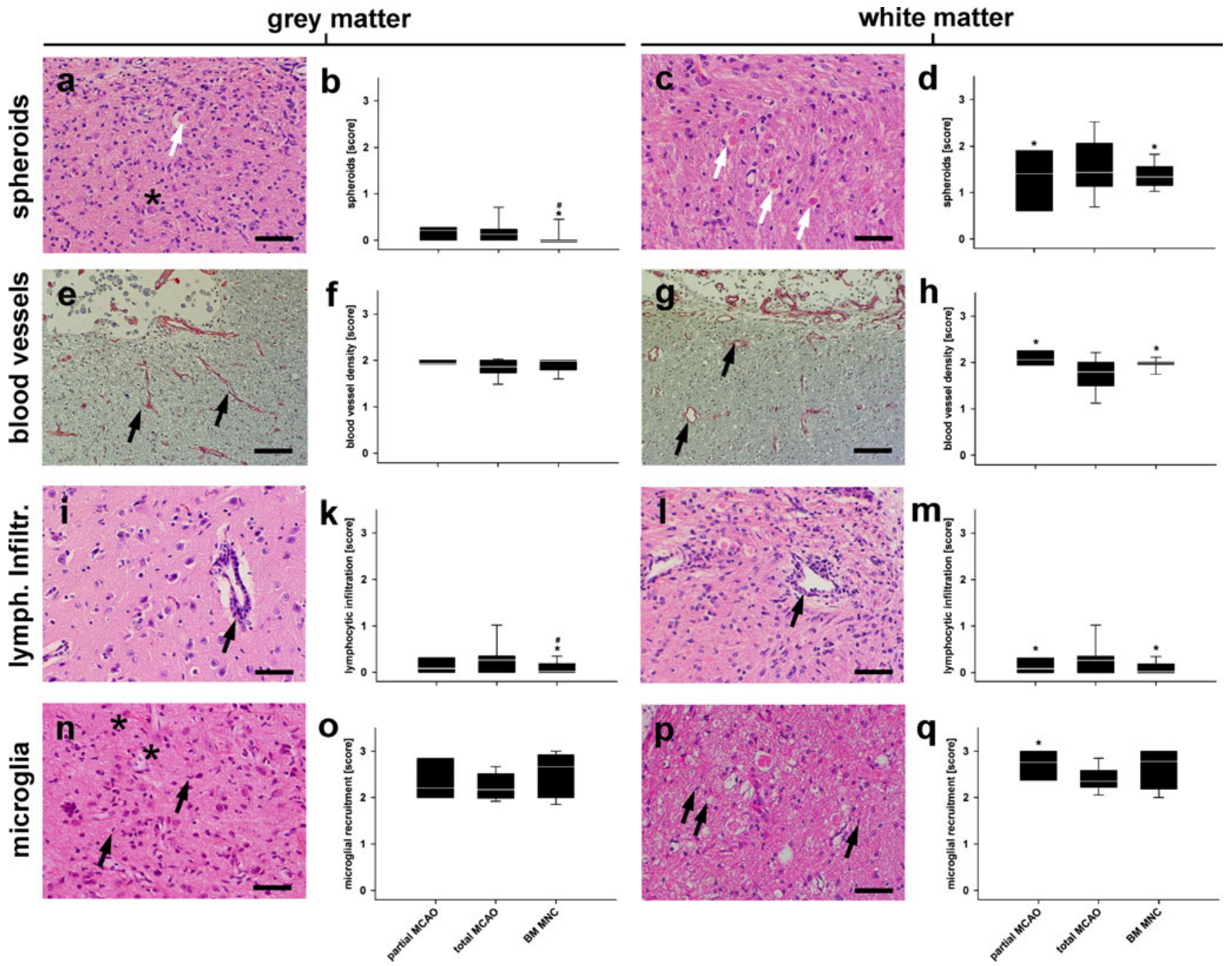

Fig. 5 Histopathological changes in the reactive zone. As expected, only a few spheroids were identified in grey matter (a, white arrow, $\mathrm{HE}$, and b). In some cases, few (degenerated) neuronal were also observed ("ghost cells"; $\mathbf{a}$ and $\mathbf{n}$, black asterisks). In white matter, the number of degenerated axons (c, white arrow, HE) was generally higher (d). The number of spheroids was smaller in BM MNC group in both areas, and reduced in partial MCAO subjects in the white matter. $(p<0.05$, b and d). Blood vessel (e and $\mathbf{g}$, black arrows, Picrosirius red) density was indifferent in the grey matter of all groups (f), but was enhanced in the white matter of partial MCAO and BM MNC subjects (h). Perivascular infiltrations (i and $\mathbf{l}$, black arrows, $\mathrm{HE}$ ) were reduced in grey and white matter of BM MNC animals as compared to total MCAO $(\mathbf{k}, p<0.05)$. In white matter, those

infiltrations were also smaller in partial as compared to total MCAO $(\mathbf{m}, p<0.05)$. Microglial recruitment was indifferent between all groups in grey matter ( $\mathbf{n}$ and $\mathbf{o}$, black arrows, $p>0.05$ ), but a significant increase was observed after partial MCAO as compared to total MCAO ( $\mathbf{p}$ and $\mathbf{q} ; p<0.05$ ). Microglial response after BM MNC treatment did not differ from other groups in white matter $(\mathbf{q}, p>0.05)$. However, note the relatively high inter-individual variance in the BM MNC group (a). All photomicrographs were taken from a total MCAO subject, graphs: white line in box plots indicates the median; whiskers give the $95 \%$ confidence interval. $* / \# p<0.05$ versus total $\mathrm{MCAO/partial} \mathrm{MCAO.} \mathrm{Scale} \mathrm{bars} \mathrm{represent} 50 \mu \mathrm{m}$ in (a), (c), (i), (l), (n) and (p), and $100 \mu \mathrm{m}$ in (e) and (g), respectively 
more spheroids could be observed in the white matter areas of the reactive zone of all groups (Fig. 5c). Here, the number of degenerated axons after total MCAO was significantly higher than in the partial MCAO group ( $p<$ 0.05 , Fig. 5d). Blood vessel (Fig. 5e and f) density (compared to the contralateral hemisphere) was indifferent in the grey matter reactive zones of partial and total MCAO groups ( $p>0.05$, Fig. $5 \mathrm{f}$ ), but was significantly lower in the white matter reactive zones of total MCAO animals $(p<$ 0.05 , Fig. $5 \mathrm{~g}$ and $\mathrm{h}$ ). Grey matter perivascular infiltration with lymphocytes (Fig. 5i and k) was similar in partial and total MCAO ( $p>0.05$, Fig. $5 \mathrm{k})$. In the white matter, lymphocyte infiltrations were found to be less frequent in the partial MCAO than in total MCAO subjects $(p<0.05$, Fig. 51 and $\mathrm{m}$ ). Microglial recruitment was generally increased following stroke. No statistically significant differences were observed between partial and total MCAO in the grey matter areas ( $p>0.4$, Fig. $5 \mathrm{n}$ and o). However, there was a surprising increase of microglial cells in the white matter areas of partial MCAO subjects $(p<0.05$, Fig. $5 p$ and q).

\section{Histological Findings in the Remote Zone and the Contralateral Hemisphere}

In the grey matter of the ipsilateral remote zone and the contralateral hemisphere, clear signs for hypoxic-ischaemic neuronal alterations were found among all groups except for sham animals. However, in the white matter areas, the number of spheroids was less in the partial MCAO as compared to the total MCAO group ( $p<0.05$, Fig. 6a). Blood vessel density was statistically indifferent between groups and between grey and white matter areas in the remote zone, although higher median score values were assessed for partial MCAO in cortical and medullary areas against total MCAO ( $p>0.05$, Fig. 6b). Interestingly, perivascular lymphocytic infiltrations were clearly observable in the total MCAO group, but were almost undetectable in the partial MCAO group $(p<0.05$, Fig. $6 c$; no quantitative data is shown for Fig. $6 a$ to $c$ ). Pathological findings were always less pronounced in the contralateral hemisphere.

There was an overall slight to moderate increase of microglial activation in the remote zones and contralateral hemispheres of partial and total MCAO subjects, which did not differ statistically between the groups in the remote zone ( $p>0.4$, data not shown) and in the contralateral hemisphere ( $p>0.05$, Fig. $6 \mathrm{~d})$.

Part II: Impact of Autologous BM MNC Therapy on Permanent Total Cortical MCAO

\section{Gross Pathology and Volumetry}

Initial lesion size determined at day 1 by MRI showed no difference between both, treated (BM MNC) and untreated (control) total MCAO groups ( $p>0.4$, Fig. $2 \mathrm{a}$ and b). In contrast, the lesion extension was significantly larger in untreated MCAO animals as compared to the BM MNC group $\left(21.5 \pm 2.2 \mathrm{~cm}^{2}\right.$ versus $12.0 \pm 3.0 \mathrm{~cm}^{2} ; p<0.01$, Fig. $2 \mathrm{c}$
Fig. 6 Findings in the remote zone and the contralateral hemisphere. Axonal alterations concerning spheroids were less prominent in the remote zone and the contralateral hemisphere (a, black arrows, HE) as compared to the reactive zone. The same situation was found for blood vessels (b, black arrows, $\mathrm{HE})$ and perivascular infiltrations (c, black arrows). All representative images were taken from the remote zone of a total MCAO subject. For the slight inter-group differences (in general less alterations in BM MNC animals), please see main text. Microglial recruitment after total MCAO was diminished in the contralateral hemisphere by BM MNC treatment (d). Scale bars represent $100 \mu \mathrm{m}$ in (a) and (b) and $50 \mu \mathrm{m}$ in (c)
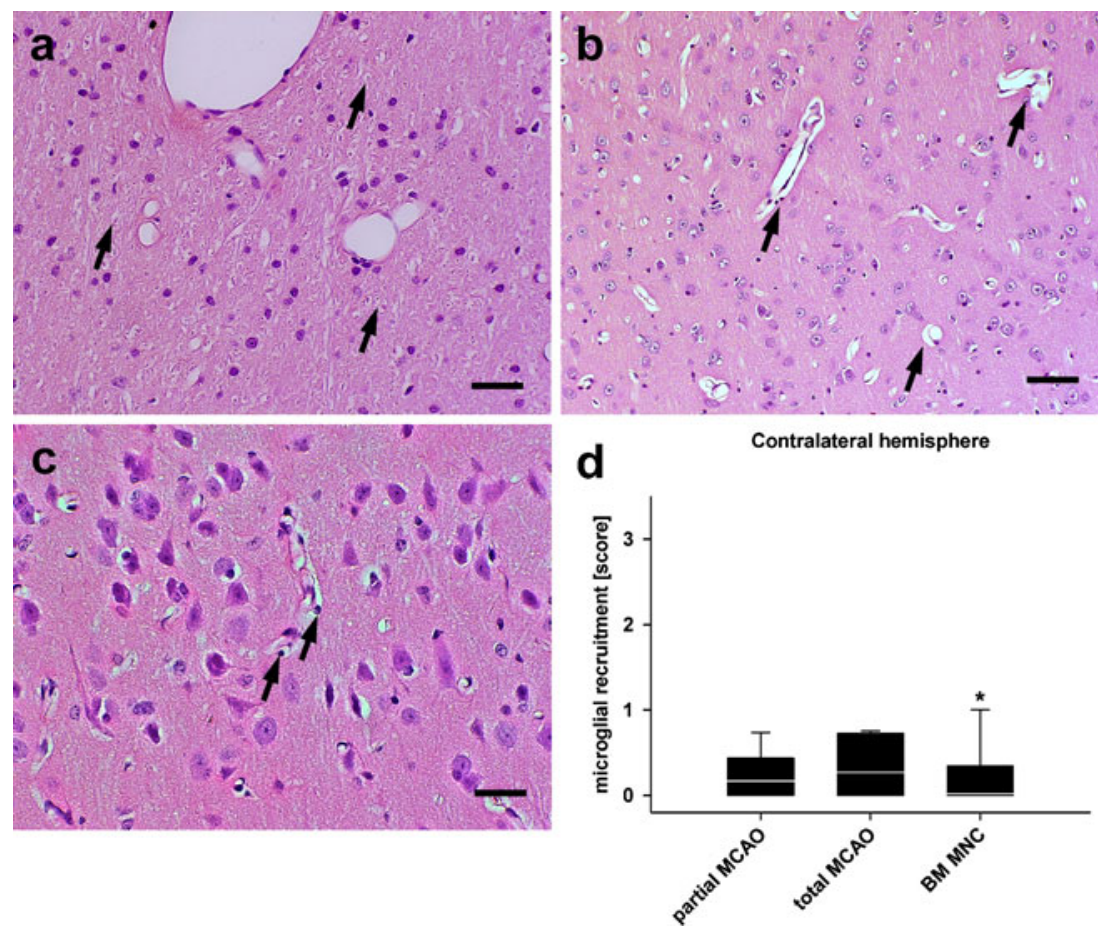
and d) at day 49. Ventricular expansion was also larger in the total MCAO group $(2.9 \pm 0.3)$ as compared to $\mathrm{BM}$ MNC-treated subjects $(2.0 \pm 0.2 ; p<0.05$, Fig. $2 \mathrm{e}$ and $\mathrm{f})$.

\section{Histological Findings in the Leptomeninx}

As in other MCAO groups, a non-infectious fibrosis accompanied by mononuclear cells infiltration into the leptomeninx was observed in BM MNC-treated subjects. In the lesioned hemisphere, connective tissue proliferation was indifferent between $\mathrm{BM} \mathrm{MNC}$ treatment and untreated partial or total MCAO animals (Fig. 3a and b-f, $p>0.05$ ). However, lymphocytic infiltration after autologous BM MNC transplantation as compared to partial and total MCAO group ( $p<0.05$, Fig. $3 \mathrm{~g}$ and $\mathrm{h})$. Remarkably, this was the case for both hemispheres $(p<0.05$ each).

\section{Histological Findings in the Central Zone}

Connective tissue proliferation in the BM MNC group was similar to the partial MCAO group and slightly enhanced in comparison to the untreated total MCAO group $(p<0.05$, Fig. $4 \mathrm{a}-\mathrm{c})$. No differences were observed regarding blood vessel density ( $p>0.4$, Fig. $4 d$ and e). Lymphocytic infiltration was also found to be significantly lower in the BM MNC group as compared to the control MCAO animals $(p<0.01$, Fig. 4f and g). Mineral deposits were indifferent between all groups in grey and white matter $(p>$ 0.05 , Fig. $4 \mathrm{~h}$ and i), but highest median values were observed for the BM MNC group.

\section{Histological Findings in the Reactive Grey and White Matter Zones}

Seven weeks after MCAO, cytolytic neurons were rarely found in the reactive grey matter (cortical) zone of BM MNC-treated subjects. As in the partial MCAO group, only few post-ischaemic neurons were observed in the reactive cortical areas of BM MNC animals. These events were less frequent than in untreated total MCAO subjects $(p<0.01)$. Numbers of spheroids were significantly lower in grey matter areas after BM MNC transplantation $(p<0.05$, Fig. 5b). In accordance to findings from untreated partial and total MCAO subjects, more spheroids were found in the white matter areas of the reactive zone in BM MNCtreated animals (Fig. 5c). BM MNC treatment reduced the amount of degenerated axons after total MCAO $(p<0.05$, Fig. 5d). While autologous BM MNC treatment did not alter blood vessel density in the grey matter areas of the reactive zone (Fig. 5e and f), a significantly higher number of blood vessels was observed in the white matter of celltreated subjects as compared to untreated total MCAO ( $p>$ 0.05 , Fig. $5 \mathrm{~g}$ and $\mathrm{h})$. Perivascular infiltration with lympho- cytes (Fig. 5i and k) was lower in the grey matter of BM MNC subjects as compared to partial and total MCAO $(p<$ 0.05 , Fig. $5 \mathrm{k}$ ). In the white matter of BM MNC-treated animals, lymphocyte infiltration was also lower as compared to total MCAO ( $p<0.05$, Fig. 51 and $m$ ). The amount of infiltrating lymphocytes was indifferent from that after partial MCAO $(p<0.05)$. Results regarding microglial recruitment showed a high inter-individual variance. Albeit higher median score values in BM MNC-treated subjects, there was no difference between total MCAO with or without BM MNC treatment in the grey matter $(p>0.05$, Fig. 5o) and white matter ( $p>0.05$, Fig. $5 q)$ reactive zones.

\section{Histological Findings in the Remote Zone and the Contralateral Hemisphere}

In general, pathological findings in the BM MNC group were nearly comparable to the situation found in untreated total MCAO. Notwithstanding this, BM MNC treatment resulted in an amelioration of axonal degeneration in the white matter of the remote zone and the contralateral hemisphere after total MCAO ( $p<0.05$, Fig. 6a). While blood vessel density was not statistically different after cell treatment ( $p>0.05$, Fig. 6b), perivascular lymphocytic infiltrations were absent in BM MNC-treated animals $(p<$ 0.05 , Fig. $6 c$ ). However, there was a decrease in microglial recruitment after BM MNC treatment in the contralateral hemisphere ( $p<0.05$, Fig. $6 \mathrm{~d})$ compared to untreated total MCAO animals.

\section{Discussion}

\section{Gross Pathology and Volumetry}

In all animals observed, induction of MCAO was associated with a loss of functional tissue in the effected hemisphere. As expected, the final lesion extension differed between partial and total MCAO subjects. Similar findings were already reported for imaging and behavioural endpoints in that model [24]. Albeit indifferent MRI results between total MCAO and BM MNC subjects at day 1, the final lesion extension in BM MNC subjects was closer to the partial MCAO group, rather than to the total MCAO group. This indicates that autologous BM MNC administration may have the potential to ameliorate the consequences of ischaemic stroke, which is in accordance with previous findings. Beneficial impact of intravenous [13] and intra-arterial [30] administration of BM MNC on lesion size has been reported. However, relatively short (45 min), transient occlusions of the middle cerebral artery were performed in both studies. Though the therapeutic impact of BM MNC administration could be clearly demonstrated 
in these models, the vessel occlusion time was much shorter than the average onset-to-needle-time reported for human stroke patients being successfully subjected to thrombolysis $[31,32]$. Moreover, cell therapies may represent a treatment option for patients being ineligible for thrombolysis. In those patients, long lasting $(>24 \mathrm{~h})$ or even permanent vessel occlusion is common. To the best of our knowledge, the present study for the first time gives evidence that autologous BM MNC administration may be effective after permanent MCAO and in the gyrencephalic brain.

Neuronal Loss, Axonal Degeneration and Blood Vessel Density Following Stroke in Sheep

The loss of cortical neurons and subsequent axonal degeneration in the white matter is an important histological correlate for functional disabilities following stroke. The presence of cytolytic neuronal alterations was only rarely seen in areas of the reactive zone bordering the central lesion. This might be attributed to the permanent occlusion modality resulting in a sharply demarked ischaemic area, and the prolonged survival period of 7 weeks in which most of the cytolytic neurons and cell debris has been removed by phagocytes.

Clear differences between the groups were observed regarding signs of axonal degeneration. Because cortical areas predominantly contain neuronal somata, signs for axonal degeneration are generally rare in grey matter areas [33]. Nevertheless, there was a statistically significant reduction of grey matter axonal degeneration after BM MNC treatment as compared to partial and total MCAO subjects. In the white matter areas of the reactive and remote zones, axonal alteration was observed to a smaller extend in animals subjected to partial MCAO. Less frequent axonal degeneration in white matter areas in the partial MCAO group can be explained by a smaller initial lesion size, subsequently resulting in the degeneration of a smaller number of fibre tracts. However, a reduced frequency of axonal degeneration was also found after BM MNC treatment of total MCAO, being comparable to the situation after partial MCAO. This was the case in both, the reactive and the remote zones of the ipsilateral hemisphere. As the initial size of the ischaemic lesion was comparable between untreated and BM MNC-treated total MCAO subjects, these differences are more likely related to processes in the sub-acute or chronic stage. In fact, BM MNC have been reported to enhance axonal sprouting and brain plasticity following stroke [12] in the rat. Protection against ischaemic white matter damage by BM MNC was also shown to be associated with augmented cerebral blood flow in the affected areas [34], indicating a close relationship between post-stroke vascularisation, cerebral blood flow and white matter protection. BM MNC may enhance vascularisation and blood flow by stimulating the proliferation of endog- enous endothelial precursor cells [35]. The stimulation of neural stem and precursor cells in the neuro-vascular niche [35] may further contribute to enhanced plasticity after focal cerebral ischaemia. In fact, an increased number of blood vessels were observed in reactive white areas of the BM MNC-treated sheep in this study. These areas are considered to be highly relevant for post-stroke brain plasticity and functional regeneration [36]. Nevertheless, more detailed information regarding the in vivo situation, for example using diffusion tensor MRI technologies and correlation with neurofunctional outcome will be needed to verify reported findings in more detail.

Lymphocytic Infiltration as a Major Component of Stroke Pathophysiology

Lymphocytic infiltrations have been identified as a major contributor to infarct size and loss of function following stroke [37]. Consequently, post-stroke inflammatory processes, which may last for several days to weeks after the initial ischaemic event [38], are currently being discussed as a promising therapeutic target [39]. In our study, the number and frequency of perivascular lymphocytic infiltrations was found to be increased after a larger stroke (total $\mathrm{MCAO})$ in all investigated areas including the contralateral hemisphere. Interestingly, autologous BM MNC administration was able to reduce these events after total MCAO to the level of a smaller initial lesion (partial MCAO). Lymphocytic infiltrations were virtually absent in the contralateral hemisphere following BM MNC administration. As lymphocytic infiltrations are part of a post-stroke immunoresponse [40], this may emphasize the immunomodulatory impact of the cells. Immunomodulatory effects have been shown for mesenchymal stem cells from bone marrow [41] as well as for umbilical cord blood MNC [42]. Moreover, neuroprotective and anti-inflammatory mechanisms of BM MNC were recently demonstrated in vitro [8]. In the context of these findings, an immunomodulatory effect of BM MNC after cerebral ischaemia may also be assumed for the in vivo situation. However, it still remains unclear how and to which extend BM MNC can contribute to the amelioration of post-stroke inflammation. Thus, more detailed analysis of infiltrating lymphocyte populations, for example by means of immunohistochemistry and molecular biology is needed while the kinetic of the process will have to be elucidated as well. Thereby, the sheep stroke model may also be used to verify findings that had previously been obtained in rodent models.

Microglial Recruitment Following Stroke

As expected, there was a clear recruitment of microglial cells following all MCAO modalities in response to the 
ischaemic lesion. In the ipsilateral hemisphere, there was a surprising increase of microglial response after partial MCAO as compared to total MCAO. Comparable median values were observed after BM MNC treatment, but did not reach the level of statistical significance, probably due to high inter-individual variation. Some authors suggest that an initially decreased, but later increased recruitment of microglial cells (and thereby stimulation of the release of microglial-borne mediators like brain-derived neurotrophic factor) in reactive and remote areas may represent a proregenerative phenomenon [43]. However, as no data regarding initial microglial activation following partial and total MCAO (with or without BM MNC treatment) was obtained in this study, a direct comparison with our data would be speculative. In the contralateral hemisphere, BM MNC treatment reduced microglial recruitment as compared to total MCAO, indicating an overall (speculatively even systemic) anti-inflammatory effect of cell treatment. This confirms recent results from in vitro studies, monitoring the impact of BM MNC after hypoxic-ischaemic cell damage [10].

\section{Post-stroke Encrustations/Mineral Deposits}

The highest median mineralisation scores in all areas were observed in the central necrotic area and the reactive zones of BM MNC-treated subjects, although no statistically significant difference was observed between the groups. A comparatively large inter-individual variance could have contributed to this lack of statistical evidence.

This finding is important as (lack of) calcification and mineral deposits is an important safety criterion for BM MNC-based treatment after myocardial infarction. Albeit an increased rate of such events was not detectable in human patients in short- [44] and long-term [45] observations, these findings cannot simply be transferred to the situation in the brain. Thus, thorough assessment of possibly enhanced mineralisation, its precise location (intra- versus extravascular, grey versus white matter) and its relevance will be important in further translational studies, as intracerebral mineral deposits represent a risk factor for ischaemic stroke [46] and thus may be detrimental for functional recovery following cerebral ischaemia.

\section{Histological Consequences of Stroke in Inter-species Comparison}

Chronic non-infectious fibrosis of the leptomeninx is a common finding in human specimen [47]. An excessive inflammatory response following stroke is well-known for the human situation [48] and includes a reaction of meningeal cells, which form collagen type I and III during and after hypoxic-ischaemic conditions [49]. This is interpreted as part of the reorganisation processes in the necrotic zone [49]. Interestingly, such processes can only be observed up to day 15 in the rat [50], but are ongoing for weeks in human patients [51], as observed in sheep. Thus, the sheep model can be considered to be closer to the human situation in this aspect.

The inflammatory situation of the central zone 7 weeks post MCAO in sheep is characterized by macrophages and lymphocytes. This is in accordance to findings in humans, where the presence of these cells is typical for chronic stage after stroke [51] and can persist up to 53 years. Differences in the cellular component of post-stroke inflammation were reported in other large animal models, in which a dominance of leukocytes with polymorph-shaped nuclei was observed [52] after stroke induction using a suture model. In the reactive and remote zones of the infarct, typical signs of neuronal alterations were observed in sheep, including axonal degeneration (spheroids) in white matter. This is also in accordance with findings in human brain specimen, where signs of hypoxic-ischaemic cell changes can be observed until day 60 [51] and spheroids may even persist. In summary, histological investigation following stroke in sheep revealed typical histological changes after ischaemic stroke previously reported in human patients. As the ovine stroke model, in contrast to rodent models, offers the option to investigate these processes in a gyrencephalic brain, it may represent a proper tool for translational stroke research.

\section{Conclusions}

The importance of large animal models in translational stroke research was highlighted by the "Stroke Therapy Academic Industry Roundtable" (STAIR) and STEPS expert consortia $[18,19,23]$ and may be important to prevent future failures in clinical translation of cell-based therapies. In this study, the ovine stroke model was found to be an adequate model to study the histopathological alterations and damage following stroke in a gyrencephalic brain. Consequences of cerebral ischaemia were found to be similar to those observed after stroke in humans. In accordance to the already reported impact of lesion size on behavioural phenotyping [24], a pathohistological dimension showing diminished histopathological consequences after smaller lesions could be added by this study.

Preclinical data on biodistribution, dose-dependency, therapeutic time window and safety endpoints are pivotal for clinical translation of any novel therapeutic concept. In the field of cell-based therapies, these data are predominantly available from small animal models, which are crucial for preclinical research, but may not provide optimal prediction of the situation in human patients. The sheep 
model may help to bridge this gap in translational stroke research. In this study, first evidence for potential beneficial impact of autologous BM MNC therapies in the species was reported. However, to further assess the impact of BM MNC therapy on ischaemic stroke in this large animal model, additional studies will be needed focusing on imaging and behavioural endpoints, as well as aspects of astroglial modulations and more detailed description of microglial response following stroke.

Acknowledgements The authors would like to thank Dr. Anne Reischauer for technical and scientific assistance during pathohistological evaluations as well as Mrs. Maritta Wipplinger and Mrs. Silke Lehnert for technical support. We are further grateful to Prof. Dr. Uwe Gille, for surgical assistance and scientific advice.

Portions of this study were supported by structural funds of the European Union, granted by the Development Bank of Saxony (Sächsische Aufbau Bank, SAB) as well as the German Federal Ministry for Education and research (Bundesministerium für Bildung und Forschung, BMBF).

Conflict of Interest No scientific or financial conflict of interest needs to be stated by any author.

\section{References}

1. Kolominsky-Rabas PL, Heuschmann PU, Marschall D, Emmert M, Baltzer N, Neundörfer B, et al. Lifetime cost of ischemic stroke in Germany: results and national projections from a population-based stroke registry: the Erlangen Stroke Project. Stroke. 2006;37(5):1179-83.

2. Deb P, Sharma S, Hassan KM. Pathophysiologic mechanisms of acute ischemic stroke: an overview with emphasis on therapeutic significance beyond thrombolysis. Pathophysiology. 2010;17 (3):197-218.

3. Hacke W, Kaste M, Bluhmki E, Brozman M, Dávalos A, Guidetti $\mathrm{D}$, et al. Thrombolysis with alteplase 3 to 4.5 hours after acute ischemic stroke. N Engl J Med. 2008;359(13):1317-29.

4. García-Moncó JC, Pinedo A, Escalza I, Ferreira E, Foncea N, Gómez-Beldarrain M, et al. Analysis of the reasons for exclusion from tPA therapy after early arrival in acute stroke patients. Clin Neurol Neurosurg. 2007;109(1):50-3.

5. Barber PA, Zhang J, Demchuk AM, Hill MD, Buchan AM. Why are stroke patients excluded from TPA therapy? An analysis of patient eligibility. Neurology. 2001;56(8):1015-20.

6. Hess DC, Borlongan CV. Cell-based therapy in ischemic stroke. Expert Rev Neurother. 2008;8(8):1193-201.

7. Uccelli A, Benvenuto F, Laroni A, Giunti D. Neuroprotective features of mesenchymal stem cells. Best Pract Res Clin Haematol. 2011;24(1):59-64.

8. Kassis I, Vaknin-Dembinsky A, Karussis D. Bone marrow mesenchymal stem cells: agents of immunomodulation and neuroprotection. Curr Stem Cell Res Ther. 2011;6(1):63-8.

9. Li Y, Chen J, Zhang CL, Wang L, Lu D, Katakowski M, et al. Gliosis and brain remodeling after treatment of stroke in rats with marrow stromal cells. Glia. 2005;49(3):407-17.

10. Sharma S, Yang B, Strong R, Xi X, Brenneman M, Grotta JC, et al. Bone marrow mononuclear cells protect neurons and modulate microglia in cell culture models of ischemic stroke. J Neurosci Res. 2010;88(13):2869-76.
11. Brenneman M, Sharma S, Harting M, Strong R, Cox Jr CS, Aronowski J, et al. Autologous bone marrow mononuclear cells enhance recovery after acute ischemic stroke in young and middleaged rats. J Cereb Blood Flow Metab. 2010;30(1):140-9.

12. Giraldi-Guimarães A, Rezende-Lima M, Bruno FP, MendezOtero R. Treatment with bone marrow mononuclear cells induces functional recovery and decreases neurodegeneration after sensorimotor cortical ischemia in rats. Brain Res. 2009;1266:108-20.

13. Iihoshi S, Honmou O, Houkin K, Hashi K, Kocsis JD. A therapeutic window for intravenous administration of autologous bone marrow after cerebral ischemia in adult rats. Brain Res. 2004;1007(1-2):1-9.

14. Yang B, Strong R, Sharma S, Brenneman M, Mallikarjunarao K, $\mathrm{Xi} \mathrm{X}$, et al. Therapeutic time window and dose response of autologous bone marrow mononuclear cells for ischemic stroke. J Neurosci Res. 2011;89(6):833-9.

15. Battistella V, de Freitas GR, da Fonseca LM, Mercante D, Gutfilen B, Goldenberg RC, et al. Safety of autologous bone marrow mononuclear cell transplantation in patients with nonacute ischemic stroke. Regen Med. 2011;6(1):45-52.

16. Lees KR, Barer D, Ford GA, Hacke W, Kostulas V, Sharma AK, et al. Tolerability of NXY-059 at higher target concentrations in patients with acute stroke. Stroke. 2003;34(2):482-7.

17. O'Collins VE, Macleod MR, Donnan GA, Horky LL, van der Worp BH, Howells DW. 1,026 experimental treatments in acute stroke. Ann Neurol. 2006;59(3):467-77.

18. Stem Cell Therapies as an Emerging Paradigm in Stroke Participants. Stem cell therapies as an emerging paradigm in stroke (STEPS): bridging basic and clinical science for cellular and neurogenic factor therapy in treating stroke. Stroke. 2009;40 (2):510-5.

19. Savitz SI, Chopp M, Deans R, Carmichael ST, Phinney D, Wechsler L. Stem cell therapy as an emerging paradigm for stroke (STEPS) II. Stroke. 2011;42(3):825-9.

20. Kang BT, Jang DP, Gu SH, Lee JH, Jung DI, Lim CY, et al. MRI features in a canine model of ischemic stroke: correlation between lesion volume and neurobehavioral status during the subacute stage. Comp Med. 2009;59(5):459-64.

21. Heiss WD, Graf R, Wienhard K. Relevance of experimental ischemia in cats for stroke management: a comparative reevaluation. Cerebrovasc Dis. 2001;11(2):73-81.

22. Pappata S, Fiorelli M, Rommel T, Hartmann A, Dettmers C, Yamaguchi $\mathrm{T}$, et al. PET study of changes in local brain hemodynamics and oxygen metabolism after unilateral middle cerebral artery occlusion in baboons. J Cereb Blood Flow Metab. 1993;13(3):416-24.

23. Finklestein SP, Fisher M, Furlan AJ, Goldstein LB, Gorelick PB, Kaste $M$, et al. Recommendations for standards regarding preclinical neuroprotective and restorative drug development. Stroke. 1999;30(12):2752-8.

24. Boltze J, Förschler A, Nitzsche B, Waldmin D, Hoffmann A, Boltze CM, et al. Permanent middle cerebral artery occlusion in sheep: a novel large animal model of focal cerebral ischemia. J Cereb Blood Flow Metab. 2008;28(12):1951-64.

25. Abramoff MD, Magelhaes PJ, Ram SJ. Image processing with ImageJ. Biophotonics International. 2004;11(7):36-42.

26. Ellison D, Love S, Chimelli L, Harding BN, Lowe J, Vinters H. Neuropathology - a reference text of CNS pathology. 2nd ed. London: Mosby; 2004.

27. Böck P. Romeis-Mikroskopische Technik. 17th ed. Munich: Verlag Urban und Schwarzenberg; 1989.

28. Junqueira LC, Bignolas G, Brentani RR. Picrosirius staining plus polarization microscopy, a specific method for collagen detection in tissue sections. Histochem J. 1979;11(4):447-55. 
29. Constantine VS, Mowry RW. Selective staining of human dermal collagen. II. The use of picrosirius red F3BA with polarization microscopy. J Invest Dermatol. 1968;50(5):419-23.

30. Baker AH, Sica V, Work LM, Williams-Ignarro S, de Nigris F, Lerman LO, et al. Brain protection using autologous bone marrow cell, metalloproteinase inhibitors, and metabolic treatment in cerebral ischemia. Proc Natl Acad Sci U S A. 2007;104 (9):3597-602.

31. Ferrari J, Knoflach M, Kiechl S, Willeit J, Matosevic B, Seyfang L, et al. Stroke thrombolysis: having more time translates into delayed therapy: data from the Austrian Stroke Unit Registry. Stroke. 2010;41(9):2001-4.

32. Szoeke CE, Parsons MW, Butcher KS, Baird TA, Mitchell PJ, Fox $\mathrm{SE}$, et al. Acute stroke thrombolysis with intravenous tissue plasminogen activator in an Australian tertiary hospital. Med J Aust. 2003;178(7):324-8.

33. Feigin I, Budzilovich G, Weinberg S, Ogata J. Degeneration of white matter in hypoxia, acidosis and edema. J Neuropathol Exp Neurol. 1973;32(1):125-43.

34. Fujita Y, Ihara M, Ushiki T, Hirai H, Kizaka-Kondoh S, Hiraoka $\mathrm{M}$, et al. Early protective effect of bone marrow mononuclear cells against ischemic white matter damage through augmentation of cerebral blood flow. Stroke. 2010;41(12):2938-43.

35. Nakano-Doi A, Nakagomi T, Fujikawa M, Nakagomi N, Kubo S, $\mathrm{Lu} \mathrm{S}$, et al. Bone marrow mononuclear cells promote proliferation of endogenous neural stem cells through vascular niches after cerebral infarction. Stem Cells. 2010;28(7):1292-302.

36. Andres RH, Horie N, Slikker W, Keren-Gill H, Zhan K, Sun G, et al. Human neural stem cells enhance structural plasticity and axonal transport in the ischaemic brain. Brain. 2011;134(6):1777-89.

37. Brait VH, Jackman KA, Walduck AK, Selemidis S, Diep H, Mast $\mathrm{AE}$, et al. Mechanisms contributing to cerebral infarct size after stroke: gender, reperfusion, $\mathrm{T}$ lymphocytes, and Nox2-derived superoxide. J Cereb Blood Flow Metab. 2010;30(7):1306-17.

38. Endres M, Dirnagl U. Ischemia and stroke. Adv Exp Med Biol. 2002;513:455-73.

39. Tuttolomondo A, Di Sciacca R, Di Raimondo D, Renda C, Pinto A, Licata G. Inflammation as a therapeutic target in acute ischemic stroke treatment. Curr Top Med Chem. 2009;9 (14):1240-60.

40. Gelderblom M, Leypoldt F, Steinbach K, Behrens D, Choe CU, Siler DA, et al. Temporal and spatial dynamics of cerebral immune cell accumulation in stroke. Stroke. 2009;40(5):1849-57.

41. Ohtaki H, Ylostalo JH, Foraker JE, Robinson AP, Reger RL, Shioda S, et al. Stem/progenitor cells from bone marrow decrease neuronal death in global ischemia by modulation of inflammatory/ immune responses. Proc Natl Acad Sci U S A. 2008;105 (38): $14638-43$.

42. Leonardo CC, Hall AA, Collier LA, Ajmo Jr CT, Willing AE, Pennypacker KR. Human umbilical cord blood cell therapy blocks the morphological change and recruitment of CD11b-expressing, isolectin-binding proinflammatory cells after middle cerebral artery occlusion. J Neurosci Res. 2010;88(6):1213-22.

43. Madinier A, Bertrand N, Mossiat C, Prigent-Tessier A, Beley A, Marie $\mathrm{C}$, et al. Microglial involvement in neuroplastic changes following focal brain ischemia in rats. PLoS One. 2009;4(12): e8101.

44. Tse HF, Thambar S, Kwong YL, Rowlings P, Bellamy G, McCrohon J, et al. Safety of catheter-based intramyocardial autologous bone marrow cells implantation for therapeutic angiogenesis. Am J Cardiol. 2006;98(1):60-2.

45. Leistner DM, Fischer-Rasokat U, Honold J, Seeger FH, Schachinger $\mathrm{V}$, Lehmann R, et al. Transplantation of progenitor cells and regeneration enhancement in acute myocardial infarction (TOPCARE-AMI): final 5-year results suggest long-term safety and efficacy. Clin Res Cardiol. 2011;100(3):187-2.

46. Chen XY, Lam WW, Ng HK, Fan YH, Wong KS. Intracranial artery calcification: a newly identified risk factor of ischemic stroke. J Neuroimaging. 2007;17(4):300-3.

47. Schade JP, McMenemey WH, Council for International Organizations of Medical Sciences. Selective vulnerability of the brain in hypoxaemia: proceedings of a symposium organized by the Council for International Organizations of Medical Sciences. Oxford: Blackwell Scientific Publications; 1963.

48. Dirnagl U, Iadecola C, Moskowitz MA. Pathobiology of ischaemic stroke: an integrated view. Trends Neurosci. 1999;22 (9):391-7.

49. Sievers J, Pehlemann FW, Gude S, Berry M. Meningeal cells organize the superficial glia limitans of the cerebellum and produce components of both the interstitial matrix and the basement membrane. J Neurocytol. 1994;23(2):135-49.

50. Clark RK, Lee EV, Fish CJ, White RF, Price WJ, Jonak ZL, et al. Development of tissue damage, inflammation and resolution following stroke: an immunohistochemical and quantitative planimetric study. Brain Res Bull. 1993;31(5):565-72.

51. Mena H, Cadavid D, Rushing EJ. Human cerebral infarct: a proposed histopathologic classification based on 137 cases. Acta Neuropathol. 2004;108(6):524-30.

52. Kang BT, Lee JH, Jung DI, Park C, Gu SH, Jeon HW, et al. Canine model of ischemic stroke with permanent middle cerebral artery occlusion: clinical and histopathological findings. J Vet Sci. 2007;8(4):369-76. 